\title{
CONSULTA DE ENFERMAGEM NO AMBULATÓRIO DE HIV/AIDS: A PERCEPÇÃO DOS USUÁRIOS
}

\author{
Simara Moreira de MACÊDO ${ }^{a}$, Márcia Cristina dos Santos SENA ${ }^{b}$, Karla Corrêa Lima MIRANDAc
}

\section{RESUMO}

O estudo busca conhecer a percepção dos usuários em relação à consulta de enfermagem em um ambulatório de Vírus da Imunodeficiência Humana/Síndrome da Imunodeficiência Adquirida (HIV/AIDS), no município de Fortaleza-CE. Trata-se de um estudo exploratório e descritivo, com abordagem qualitativa. Os dados foram coletados por meio de entrevista semiestruturada, com quinze usuários da referida instituição, e analisados com o suporte da análise de conteúdo. A consulta de enfermagem foi relatada pelos usuários como um momento de aprendizado, centrado no fornecimento de informações. A confiança e o apoio emocional, estabelecidos pelo profissional, atuam como um suporte frente aos conflitos vivenciados pelo paciente, possibilitando a construção de um novo olhar frente à doença. Acredita-se que a realização da consulta de enfermagem em uma perspectiva dialogal poderá proporcionar aos usuários a ressignificação dos conflitos que permeiam seu adoecimento.

Descritores: Síndrome de Imunodeficiência Adquirida. Enfermagem. Assistência ao paciente.

\section{RESUMEN}

El estudio intenta conocer la percepción de usuarios de la consulta de enfermería en ambulatorio de Virus de Inmunodeficiencia Humana / Síndrome de Inmunodeficiencia Adquirida (VIH/SIDA) en la ciudad de Fortaleza-CE. Se trata de un estudio explorador y descriptivo, con abordaje cualitativo. Los datos fueron recolectados por medio de entrevista semiestructurada con quince usuarios de la referida institución y analizados con base en el análisis de contenido. La consulta de enfermería fue relatada por los usuarios como un momento de aprendizaje, centrado en la suministración de informaciones. La confianza y el apoyo emocional establecido por el profesional actúan como un soporte delante de los conflictos vividos por el paciente, posibilitando la construcción de una nueva concepción de la enfermedad. Creemos que la realización de la consulta de enfermería en una perspectiva dialéctica podrá proporcionarles a los usuarios la resignificación de los conflictos presentes en su enfermedad.

Descriptores: Síndrome de Inmunodeficiencia Adquirida. Enfermería. Asistencia al paciente. Título: Consulta de enfermería en ambulatorio de VIH/SIDA: la percepción de los usuarios.

\section{ABSTRACT}

The study aims to understand the patients' perception regarding the nursing consultation at an outpatient clinic for Human Immunodeficiency Virus / Acquired Immunodeficiency Syndrome (HIV/AIDS) in the city of Fortaleza-CE (State of Ceará). This is an exploratory and descriptive qualitative approach. Data was collected through semi-structured interviews with fifteen patients of this institution and analyzed with the support of content analysis. The nursing consultation was reported by patients as a learning moment, focused on providing information. The trust and emotional support provided by the professional act as a support to the conflicts experienced by the patients, allowing the construction of a new perspective of the disease. We believe that the implementation of the nursing consultation in a dialogic perspective can provide a new meaning to the conflicts surrounding the patients' illness.

Descriptors: Acquired Immunodeficiency Syndrome. Nursing. Patient care.

Title: Nursing consultation in an HIV/AIDS outpatient clinic: patients' perception.

\footnotetext{
a Mestre em Cuidados Clínicos em Saúde e Enfermagem, Enfermeira da Estratégia Saúde da Família, Caucaia, Ceará, Brasil.

b Enfermeira da Unidade de Pronto Atendimento, Fortaleza, Ceará, Brasil.

c Doutora em Enfermagem, Docente do Programa de Pós-Graduação em Cuidados Clínicos em Saúde e Enfermagem da Universidade Estadual do Ceará, Fortaleza, Ceará, Brasil.
} 


\section{INTRODUÇÃO}

Ao pensarmos as relações no processo de cuidar no campo da enfermagem, percebemos que a ênfase no saber do especialista em detrimento da vivência subjetiva dos envolvidos e a naturalização/ biologização do sofrimento humano repercutem diretamente na possibilidade de construção de novos modelos assistenciais.

Mediante as diversas mudanças no âmbito da saúde, a partir das propostas implementadas pelo Sistema Único de Saúde (SUS) e das críticas ao modelo biomédico de assistência, tem-se proposto serviços que valorizem as particularidades de usuários assistidos, assim como a manifestação de suas subjetividades ${ }^{(1)}$.

O enfermeiro dispõe da consulta de enfermagem como uma das atividades privativas, com respaldo legal do Conselho Federal de Enfermagem desde 1986, constituída por ações sistematizadas e inter-relacionadas que visam ao cuidado ${ }^{(2)}$. Tal instrumento surge neste cenário com relevância ímpar, uma vez que proporciona ao enfermeiro condições para atuar de forma direta e independente com o cliente, ratificando a autonomia profissional.

A consulta utiliza componentes do método científico para identificar situações de saúde/ doença, prescrever e implementar medidas de enfermagem que contribuam para a promoção, prevenção e proteção da saúde. A aplicação pode ser composta pelas seguintes fases: coleta dos dados, estabelecimento dos diagnósticos de enfermagem, implementação do plano de cuidados e avaliação dos resultados ${ }^{(2)}$.

A complexidade de aplicação da consulta de enfermagem refere-se à amplitude de ação que tal atividade permite atingir a nível assistencial. Destaca-se como relevância desta atividade o desenvolvimento do relacionamento terapêutico, a promoção do acolhimento, da escuta, da educação em saúde, ou seja, ações capazes de transcender o patológico e proporcionar ambiente de conforto, confiança e bem-estar ao paciente( ${ }^{(3)}$.

Nessa perspectiva, em 1997, a consulta de enfermagem foi adotada em Ambulatório Especializado em Vírus da Imunodeficiência Humana/Síndrome da Imunodeficiência Adquirida (HIV/AIDS) em unidade de referência em doenças infecciosas no município de Fortaleza-CE, como estratégia para abordagem do cuidado individualizado com pacien- tes portadores da referida patologia, uma vez que, até então, as consultas eram realizadas pelo médico, centradas em medicalização e solicitação de exames.

Logo, o desafio consiste em desconstruir os moldes tradicionalistas, nos quais a enfermagem vem sendo pautada ao longo dos anos, desmistificando a imagem de profissão intermediadora, pacificadora, caridosa, humanista, e percebendo o potencial de ir além do que a literatura propõe através do conhecimento científico. $\mathrm{O}$ diferencial está exatamente na capacidade de o profissional apropriar-se de todos esses atributos em prol da assistência voltada para o usuário, permitindo que este ocupe lugar ativo no processo de cuidado.

O enfermeiro necessita apropriar-se de instrumentos que convoquem usuários a protagonizar suas próprias histórias, e a consulta de enfermagem pode se configurar como dispositivo para construção da prática clínica pautada nas necessidades do usuário, de forma a não priorizar apenas questões biológicas.

Em face dessas reflexões, propôs-se nesse estudo conhecer a percepção dos usuários em relação à consulta de enfermagem em um ambulatório de HIV/AIDS no município de Fortaleza-CE.

\section{METODOLOGIA}

Estudo exploratório e descritivo, com abordagem qualitativa, realizado em Serviço Ambulatorial Especializado em HIV/Aids, de hospital de referência em doenças infecciosas, em Fortaleza-CE.

Os sujeitos da pesquisa foram quinze usuários que utilizavam o referido serviço no período de realização do estudo, entre novembro de 2006 e fevereiro de 2007 , tendo sido estes escolhidos de forma aleatória. Por se tratar de uma pesquisa qualitativa, o número de sujeitos foi definido a partir do critério da saturação dos dados.

Os dados foram coletados por meio de entrevista semiestruturada com questionamentos acerca da percepção do usuário ao vivenciar a consulta de enfermagem, tendo sido esta aplicada ao paciente imediatamente após a realização da consulta.

As entrevistas foram gravadas e transcritas, constituindo o corpus do estudo. Optou-se por denominar os informantes por números de acordo com a ocorrência das entrevistas. Foi utilizado diário de campo para registrar reações percebidas por observação direta, bem como expressões não verbalizadas pelos sujeitos estudados. 
Para análise das falas, foi utilizada a técnica de análise de conteúdo por tratar-se de procedimento que parte da mensagem e possibilitar compreensão dos significados. Este método foi trabalhado seguindo-se três fases: pré-análise, exploração do material, tratamento dos resultados obtidos e interpretação ${ }^{(4)}$.

Neste estudo, optou-se pela análise temática, cuja técnica visa desmembrar o texto em unidades e categorias, realizando a interpretação e análise dos dados à luz do referencial teórico pertinente.

Diante dos dados obtidos, foram realizadas leituras exaustivas do material empírico, a constituição do corpus foi definida em quinze entrevistas, que corresponderam à totalidade dos sujeitos do estudo. Nas entrevistas, selecionaram-se as unidades de registro por meio de frases, sempre as relacionando com o objetivo do estudo. Foram obtidas 68 unidades de registro, organizadas em 15 subcategorias e trabalhadas em três categorias intituladas: informação/orientação, apoio e mudança.

O projeto de pesquisa foi avaliado e aprovado pelo Comitê de Ética em Pesquisa da instituição em que foi realizado o estudo, conforme protocolo 036/2005. Os critérios éticos para as pesquisas que envolvem seres humanos foram respeitados,

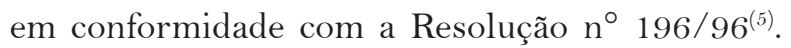
A participação dos sujeitos na pesquisa foi voluntária, estes foram esclarecidos quanto à ausência de riscos. Os sujeitos do estudo assinaram o Termo de Consentimento Livre e Esclarecido, no qual estavam explicitados os objetivos do estudo e as responsabilidades do entrevistador e do entrevistado.

\section{RESULTADOS E DISCUSSÃO}

Os quinze pacientes entrevistados foram submetidos à consulta de enfermagem. Um era do sexo feminino, os demais do masculino, com idade entre 21 e 52 anos, renda familiar de até dois salários mínimos, um residia em Fortaleza e os outros residiam em municípios no interior do Ceará.

A partir da análise dos dados foram construídas as categorias descritas.

\section{Informação/orientação}

Para os usuários entrevistados, a consulta de enfermagem se configurava como momento de aprendizado, centrado no repasse de informações e orientações que permitiam ao paciente esclarecer dúvidas.
Foi muito bom, muitas coisas que eu não sabia, ela esclareceu muitas coisas para mim (e1).

Tem que conversar mesmo, tem que esclarecer, tirar suas dúvidas tudinho (er).

\section{[…] Importante, eu aprendi mais coisas (e2).}

A informação no processo educativo e de aprendizagem é etapa fundamental ${ }^{(6,7)}$. Entretanto, faz-se necessária a participação ativa do sujeito na aprendizagem, de forma que este possa contribuir na construção do conhecimento, cujo diálogo é importante facilitador desse processo.

Durante a realização do diário de campo, foi pontuada a dificuldade de os sujeitos do estudo conseguirem aprofundar as discussões de forma crítica, emitindo imagem ingênua e resignada da assistência oferecida.

A relação profissional-paciente não deve se manifestar de forma verticalizada, em que se supõe a existência de saber como verdade absoluta, em que o paciente ocupe o papel de mero receptor de informações ${ }^{(8,9)}$.

Eu achei ótimo, falei com ela e ela me explicou bastante o que estava faltando. Isto é muito bom (e5).

Destacamos que não cabe ao profissional determinar o que "falta" ao paciente, mas permitir que ele próprio, por meio da manifestação subjetiva de desejos, anseios e dúvidas, proporcione a construção coletiva do conhecimento.

No processo educativo, os envolvidos mutuamente aprendem mediatizados pelo mundo, ou seja, profissional e paciente trocam saberes e constroem outro saber por meio do diálogo problematizador e interação mútua. Logo, o profissional ao ocupar o lugar de educador deve estimular o educando a formular sua demanda, a produzir questões, reposicionando o manejo educativo ${ }^{(10)}$.

A consulta deve ser momento em que cliente e profissional se relacionam, permutem ideias e partilhem conhecimentos e afetos, de forma que as questões existenciais sejam percebidas. Não existe saber verdadeiro, todo saber é relativo, negado, superado ou complementado por outros saberes, buscando através de movimento contínuo de diálogo e troca de experiências romper com o modelo normatizador e possibilitar a construção de formas de cuidado diferenciadas ${ }^{(8-9-11)}$. 
Apoio

Aponta-se a importância do relacionamento terapêutico na assistência de enfermagem, potencializando o processo de cuidado por meio da confiança e do apoio emocional estabelecido pelo profissional, de forma a atuar como suporte mediante conflitos vivenciados pelo paciente diante da condição de soropositividade.

Foi muito confortante. Ela me apoiou e me incentivou. Seu olhar, seu carinho foi fundamental para mim (e2).

Ela passou mais confiança para mim (e1).

O pessoal aqui se preocup a com a gente, porque eles sabem que o preconceito é muito grande (e7).

[...] e passou que tudo que eu quisesse esclarecer podia contar com ela (e1).

Tive apoio, ela foi muito comunicativa (e5).

Torna-se importante que a enfermagem seja capaz de contemplar o processo de cuidado nos variados âmbitos. Os moldes tecnicistas nos quais a profissão foi ajustada ao longo dos anos não a comportam mais, uma vez que desenvolver assistência baseada em módulos, em padrões pré-estabelecidos, não é suficiente para contemplar a complexidade dos sujeitos, fazendo-se necessárias flexibilidade e criatividade para lidar com angústias, temores e incertezas que permeiam o processo de adoecimento.

Movimento possível para desconstruir o modelo de cuidado tecnicista seria pensar o usuário como sujeito. O sujeito não deve ser tomado como indivíduo, ou seja, entidade individual, que porta uma essência. É preciso considerar a produção de subjetividade no qual o plano do desejo se articula com o social ${ }^{(12)}$

Por conseguinte, a subjetividade se configura como processo de produção do sujeito em terreno de forças que atua de maneira contínua e em relação com história e cultura. Então, existe superação na configuração do indivíduo, cujo estatuto da razão prevalece e a verdade do sujeito está ordenado pela razão. Desta forma, saberes e poderes são redes modeladoras dos processos de subjetivação ${ }^{(13)}$.

A enfermagem, ao reformular sua concepção de indivíduo para sujeito, poderia repensar a forma de cuidar e suas implicações. Ao se reconfigurarem as posições entre os sujeitos, ressignificando os sentidos produzidos, outras práticas podem surgir.

A interação profissional-paciente não deve ter cunho técnico e de informação; é imprescindível, ao mesmo tempo, lidar com questões socioculturais, psicoemocionais e éticas imersas neste processo. A reconstrução da relação terapêutica não se manifesta a partir de técnica, mas de sabedoria prática, sendo necessário unir esforços para compreensão e delineamento de ações eficazes, conforme contextos culturais específicos ${ }^{(14-15)}$.

Salienta-se que o profissional de saúde não está imune aos sentimentos trazidos pelo paciente, tendo em vista que a história de vida do cliente afetará em alguma medida o profissional. Entretanto, o profissional precisa desenvolver cuidar ético, não se deixando tomar por sentimentos de penalização, muitas vezes paralisantes frente ao paciente e à gama de sofrimentos transmitidas, para que não haja risco de despotencializar o cuidado ao outro e comprometer a capacidade ética ${ }^{(16)}$.

\section{Mudança}

Observou-se a possibilidade de a consulta de enfermagem se configurar em instrumento potencializador de mudança, de novo olhar ante a doença. Pois, o que antes era incerto e temeroso ao paciente passou a ser visto a partir de uma perspectiva de esperança, atuando como dispositivo de enfrentamento das possíveis dificuldades nas quais se depara o sujeito com aids.

Eu cheguei aqui arrasado, cheguei lá em baixo como dizem. Hoje eu estou outra pessoa, totalmente diferente (es).

Eu tenho esse problema que fosse uma coisa que se eu não tivesse, certo? Eu levo assim como se eu tivesse com uma gripe (e5).

Logo quando eu recebi o exame que era positivo para mim eu fiquei deprimido, eu emagreci muito, eu fiquei assim em casa, eu não queria sair, não queria ter amigos e depois dessa consulta melhorou muito. Só houve melhora positiva (e2).

Quando eu soube que tinha HIV eu fiquei desesperado. Ai, quer dizer, com a equipe do hospital, aí fiquei, hoje eu estou mais calmo. Para mim a vida tinha acabado e hoje não, eu acho melhor (e7). 
No serviço de saúde estudado, o diagnóstico sorológico era comunicado ao paciente por meio do aconselhamento em HIV/Aids, realizado pela equipe interdisciplinar da instituição, podendo este momento ser um ou quatro atendimentos. Neste contexto, após aconselhamento e entrega da sorologia positiva para o HIV, era realizada consulta de enfermagem. Neste momento, o paciente ainda estava elaborando seu diagnóstico sorológico, necessitando dialogar sobre o impacto da soropositividade pelo HIV em sua vida.

Assim, o profissional de enfermagem precisa estar aberto para perceber sentimentos, atitudes e comportamentos gerados pela condição da sorologia do HIV, e além de prestar informações sobre a doença, tratamento e cuidados gerais, possa estabelecer vínculo e interação com o indivíduo, a fim de auxiliá-lo na busca de estratégias de adaptação a nova realidade ${ }^{(17)}$.

O estigma tem sido ponto marcante que acompanha a aids desde surgimento, tendo em vista a associação a grupos populacionais específicos mais afetados ao início (homossexuais, usuários de drogas e trabalhadoras do sexo), assim como pela relação com doença fatal e aterrorizante ${ }^{(15)}$.

A necessidade de mudança, a qual se referiram as falas, surgiram como instinto natural de sobrevivência, de busca de esperança, pelo menos até então, como definitiva para estado de vulnerabilidade. Trata-se de espécie de ímpeto natural possível e necessário à natureza humana.

Cabe aos profissionais de saúde instigar no sujeito a busca de um "fazer sentido" na vida, o que implica em estabelecer ligações, fornecer forma, sequência e inteligibilidade aos acontecimentos que ao longo da vida evocam e provocam o retorno às experiências da turbulência emocional. A contínua atividade do "fazer sentido" surge como forma de tessitura de solo humano para a existência, de lugar humano para existir ${ }^{(18)}$.

Tal fato remete ao conceito de inédito viável, isto é, a possibilidade de construir algo em torno do sofrimento, através dos deslocamentos de valores e da assunção de novos olhares à realidade posta ${ }^{(19)}$.

Para compreender a natureza do sofrimento e aliviá-lo, urge superar a dicotomia existente entre/ teoria e a prática, entre mente/corpo e subjetividade/objetividade, centrando-se no sujeito sofredor e seu cuidado. Ao integrar essas dimensões no modelo de saúde-doença, transpôs-se da centralidade da doença para abordagem mais ampla, que inclui sujeitos e contextos ${ }^{(20)}$.
É preciso permitir aos pacientes a busca por novos conhecimentos, tornando possível superar preconceitos e construir realidade de aceitação da doença e busca de novas formas de vida. Ademais, refletir acerca da clínica de enfermagem, em que sujeitos possam por meio do olhar, da escuta, nos diferentes âmbitos das relações, produzir verdades, atribuindo sentido a estas, na tentativa de criar e recriar formas singulares de superação.

\section{CONSIDERAÇÕES FINAIS}

A consulta de enfermagem foi evidenciada pelos usuários estudados como importante instrumento de orientação, de esclarecimento de dúvidas e de enfrentamento de dificuldades, possibilitando reflexão acerca de possibilidades para se conviver com o diagnóstico de soropositividade.

A adaptação a uma relação verticalizada no processo de saúde, de um lado o profissional, detentor absoluto do saber, e do outro, o paciente, mero receptor de informações, dificulta ou impossibilita participação ativa deste no processo de cuidado, levando-os a imagem simplória e caridosa da assistência oferecida.

Nesse sentido, urge refletir sobre a atuação do profissional de saúde, em especial, do enfermeiro. O que poderíamos oferecer além de orientação e apoio? Embora reconheçamos a importância de atingirmos tais objetivos, é necessário avançar e propor uma clínica do cuidado crítica e reflexiva, em que o sujeito seja partícipe da construção de formas de subjetividades.

O enfermeiro, ao reconfigurar o olhar direcionado para o usuário, deslocando-o da posição de indivíduo para percebê-lo enquanto sujeito, poderá promover a produção de cuidado onde os desejos do usuário sejam percebidos para além das necessidades meramente biológicas.

Os resultados desta pesquisa poderão qualificar a consulta de enfermagem às pessoas com HIV/ Aids. Esta ao ser realizada em perspectiva dialogal, permitirá ao sujeito produzir seu próprio discurso, promovendo o deslocamento de valores e o despertar de percepções em busca de outros sentidos para vida ante a condição de adoecimento.

Para que ideia ora discutida seja concretizada, é essencial repensar e refazer instrumentos terapêuticos utilizados na consulta de enfermagem. Sugere-se ao grupo a articulação de reuniões mensais, visando propostas de reorganização da consulta, de forma que esta contemple questões subjetivas dos usuários atendidos. 


\section{REFERÊNCIAS}

1 Pinheiro R, Mattos R, organizadores. Construção da integralidade: cotidiano, saberes e práticas em saúde. Rio de Janeiro: Abrasco; 2003.

2 Conselho Federal de Enfermagem(BR). Resolução n. 159, de 1993: dispõe sobre a consulta de Enfermagem [Internet]. Brasília (DF): COFEN; 2011 [citado 2011 mai 19]. Disponível em: http://portalcofen. gov.br/sitenovo/node/4161

3 Diógenes MAR, Linard AG, Teixeira CAB. Comunicação, acolhimento e educação em saúde na consulta de enfermagem em ginecologia. Rev Rene.2010; $11(4): 38-46$.

4 Bardin L. Análise de Conteúdo. Lisboa: Edições 70; 1977.

5 Ministério da Saúde (BR), Conselho Nacional de Saúde. Resolução n. 196, de 10 de outubro de 1996: diretrizes e normas regulamentadoras de pesquisa envolvendo seres humanos. Brasília (DF); 1996.

6 Libâneo JC. Adeus professor, adeus professora: novas exigências educacionais e profissão docente. $13^{\mathrm{a}}$ ed. São Paulo: Cortez; 2011.

7 Gil AC. Metodologia do ensino superior. São Paulo: Atlas; 2008.

8 Alvim NAT, Ferreira MA. Perspectiva problematizadora da educação popular em saúde e Enfermagem. Texto Contexto Enferm. 2007; 16(2): 315-9.

9 Acioli S. A prática educativa como expressão do cuidado em Saúde Pública. Rev Bras Enferm. 2008; 61(1): 117-21.

10 Freire P. Conscientização: teoria e prática da libertação - uma introdução ao pensamento de PF. $3^{\mathrm{a}}$ ed. São Paulo: Moraes; 1980.

\section{Endereço da autora / Dirección del autor / Author's address}

Simara Moreira de Macêdo

Rua Mário Studart, 535, ap.402, Monte Castelo

60326-060, Fortaleza, CE

E-mail: simara.macedo@bol.com.br
11 Miranda KCL, Barroso MGT. Aconselhamento em HIV/Aids: análise à luz de Paulo Freire. Rev Latino-Am Enferm 2007; 15(1): 100-105.

12 Oliveira DC, Vidal CRPM, Silveira LC, Silva LMS. O processo de trabalho e a clínica de enfermagem: pensando novas possibilidades. Rev Enferm UERJ. 2009; 17(4): 521-26.

13 Viera NA, Silveira LC, Franco TB. A formação clínica e a produção do cuidado em saúde e na enfermagem. Rev Trab Educ Saúde. 2011; 9(1): 9-24.

14 Ayres JRCM. O cuidado, os modos de ser (do) humano e as práticas de saúde. Saúde Soc. 2004; 13(3): 16-29.

15 Garcia S, Koyama MAH. Estigma, discriminação e HIV/Aids no contexto brasileiro, 1998 e 2005. Rev Saúde Pública. 2008; 42(1): 72-83.

16 Luz PM, Miranda KCL, Teixeira JMC. As condutas realizadas por profissionais de saúde em relação à busca de parceiros sexuais de pacientes soropositivos para o HIV/aids e seus diagnósticos sorológicos. Ci Saúde Col. 2010; 15 (suppl.1): 1191-1200.

17 Maliska ICA, Padilha MI, Vieira M, Bastiani J. Percepções e significados do diagnóstico e convívio com o HIV/aids. Rev Gaúcha Enferm. 2009; 30(1): 85-91.

18 Figueiredo LC. As diversas faces do cuidar: novos ensaios de psicanálise contemporânea. São Paulo (SP): Editora Escuta; 2009.

19 Freire P. À sombra desta mangueira. $4^{\mathrm{a}}$ ed. São Paulo: Editora Olho d'Água; 2001.

20 Lacerda A, Valla VV. As práticas terapêuticas de cuidado integral à saúde como proposta para aliviar o sofrimento. In: Pinheiro R; Mattos RA. Cuidado: as fronteiras da integralidade. Rio de Janeiro: Hucitec; 2006. p.91-102.

Recebido em: 19.08.2011

Aprovado em: 09.07.2012 